\title{
Corrosion Behaviors of Carbon Steels in Artificially Simulated and Accelerated Marine Environment
}

\author{
Junsheng $W u^{1, *}$, Kun Pang ${ }^{1}$, Dongdong Peng ${ }^{1}$, Junwei Wu ${ }^{2}$, Yuxi Bao ${ }^{1}$, Xiaogang Li $^{l}$ \\ ${ }^{1}$ Corrosion and Protection Center, Institude of Advanced Materials and Technology, University of \\ Science and Technology Beijing, Beijing 100083, P.R. China \\ ${ }^{2}$ School of Materials Science and Engineering, Harbin Institute of Technology Shenzhen Graduate \\ School, Shenzhen 518055, P.R. China \\ *E-mail: wujs@ustb.edu.cn
}

doi: $10.20864 / 2017.02 .24$

Received: 17 October 2016 / Accepted: 5 December 2016 / Published: 30 December 2016

\begin{abstract}
A novel marine corrosion simulation and acceleration test device was developed to study the corrosion performances in various marine zones. The corrosion behaviors of Q235 carbon steel was studied indoor using this device for comparing with the results of outdoor exposure test. The simulation and acceleration test results showed the corrosion rate of Q235 carbon steel after corrosion testing in various simulated marine zones for 10 days are: $v_{\text {immersion zone }}=0.21 \mathrm{~mm} / \mathrm{a}, \mathrm{v}_{\text {tidal zone }}=0.24 \mathrm{~mm} / \mathrm{a}, \mathrm{v}_{\text {splash }}$ zone $=0.28 \mathrm{~mm} / \mathrm{a}, \mathrm{v}_{\text {atmosphere zone }}=0.025 \mathrm{~mm} / \mathrm{a}$. The main corrosion products are $\alpha-\mathrm{FeOOH}, \gamma-\mathrm{FeOOH}$, $\mathrm{Fe}_{3} \mathrm{O}_{4}, \mathrm{Fe}(\mathrm{OH})_{3}, \mathrm{Fe}_{8}(\mathrm{O}, \mathrm{OH})_{16} \mathrm{C}_{11.3}$ and $\mathrm{Fe}_{2} \mathrm{O}_{3}$. Among these marine zones, the samples in simulated splash zone showed the highest corrosion rate evaluated by weight loss and polarization curves and the smallest charge-transfer resistance according the EIS measurement. Obvious cracks and porous can be observed on rust layer of the samples in splash zone, indicating the corrosion products formed are instable. Compared with the corrosion behavior of Q235 carbon steel exposed outdoor in natural marine environment for 2 years, the corrosion tendency, corrosion production and electrochemical property of carbon steel in different simulated marine zones of this device are well consistent with that in actual marine corrosion tests. The device not only has excellent simulation of the major parameters and conditions in various marine zones, but also has a good acceleration performance.
\end{abstract}

Keywords: marine environment, simulated and accelerated tests, corrosion, electrochemistry, carbon steel

\section{FULL TEXT}


(C) 2017 The Authors. Published by ESG (www.electrochemsci.org). This article is an open access article distributed under the terms and conditions of the Creative Commons Attribution license (http://creativecommons.org/licenses/by/4.0/). 